\title{
Correction to: Dominance status and copulatory vocalizations among male stump-tailed macaques in Thailand
}

\author{
Aru Toyoda $^{1,2,3} \cdot$ Tamaki Maruhashi $^{4} \cdot$ Suchinda Malaivijitnond ${ }^{5,6} \cdot$ Hiroki Koda $^{3}([)$
}

Published online: 23 May 2020

(C) Japan Monkey Centre and Springer Japan KK, part of Springer Nature 2020

\section{Correction to: Primates}

$$
\text { https://doi.org/10.1007/s10329-020-00820-7 }
$$

In the original publication of the article the affiliations 1 and 3 were incorrectly published. The correct affiliations are given in this correction.

1. Academy of Emerging Science, Chubu University, Kasugai, Aichi 487-8501, Japan

3. Primate Research Institute, Kyoto University, Inuyama, Aichi 484-8506, Japan

Publisher's Note Springer Nature remains neutral with regard to jurisdictional claims in published maps and institutional affiliations.

The original article can be found online at https://doi.org/10.1007/ s10329-020-00820-7.

Aru Toyoda

atoyoda.pri.kyoto-u@ outlook.com

$\bowtie$ Hiroki Koda

koda.hiroki.7a@kyoto-u.ac.jp

1 Academy of Emerging Science, Chubu University, Kasugai, Aichi 487-8501, Japan

2 Core Research for Evolutional Science and Technology, Japan Science and Technology Agency, Saitama, Japan

3 Primate Research Institute, Kyoto University, Inuyama, Aichi 484-8506, Japan

4 Musashi University, Tokyo, Japan

5 Department of Biology, Faculty of Science, Chulalongkorn University, Bangkok 10330, Thailand

6 National Primate Research Center of Thailand, Chulalongkorn University, Saraburi 18110, Thailand 